\title{
Anti-inflammatory effect of salidroside on phorbol-12-myristate-13-acetate plus A23187-mediated inflammation in $\mathrm{HMC}-1$ cells
}

\author{
DA-WUN YANG ${ }^{1 *}$, OK-HWA KANG ${ }^{2 *}$, YOUNG-SEOB LEE ${ }^{3}$, SIN-HEE HAN $^{3}$, SANG-WON LEE $^{3}$, SEON-WOO CHA $^{3}$, \\ YUN-SOO SEO ${ }^{2}$, SU-HYUN MUN ${ }^{1}$, RYONG GONG ${ }^{1}$, DONG-WON SHIN ${ }^{4}$ and DONG-YEUL KWON ${ }^{2}$ \\ ${ }^{1}$ BK21 Plus Team, Professional Graduate School of Oriental Medicine,Wonkwang University, \\ Iksan, Jeonbuk 570-749; ${ }^{2}$ Department of Oriental Pharmacy, College of Pharmacy \\ and Wonkwang-Oriental Medicines Research Institute, Institute of Biotechnology, Wonkwang University, \\ Iksan, Jeonbuk 570-749; ${ }^{3}$ Department of Herbal Crop Research, National Institute of Horticultural and Herbal Science, \\ RDA, Eumseong, Chungbuk 369-873; ${ }^{4}$ Department of Oriental Medicine Resources, \\ Sunchon National University, Jeonnam 540-742, Republic of Korea
}

Received September 14, 2015; Accepted September 27, 2016

DOI: $10.3892 /$ ijmm.2016.2781

\begin{abstract}
Salidroside [2-(4-hydroxyphenyl)ethyl $\beta$-D-glucopyranoside (SAS)] has been identified as the most potent ingredient of the plant Rhodiola rosea L. Previous studies have demonstrated that it possesses a number of pharmacological properties, including anti-aging, anti-fatigue, antioxidant, anticancer and anti-inflammatory properties. In this study, to ascertain the molecular mechanisms responsible for the anti-inflammatory activity of SAS, we used phorbol-12-myristate-13-acetate (PMA) plus A23187 to induce inflammation in human mast cell line-1 (HMC-1). The HMC-1 cells were treated with SAS prior to being stimulated with PMA plus A23187. Pro-inflammatory cytokine production was measured by enzyme-linked immunosorbent assay (ELISA) and reverse transcription-polymerase chain reaction (RT-PCR). Western blot analysis was used to examine the activation of mitogenactivated protein kinases (MAPKs) and nuclear factor $\kappa$-light-chain-enhancer of activated B cells (NF- $\mathrm{BB}$ ). SAS inhibited the mRNA expression and production of interleukin (IL)-6, IL-8 and tumor necrosis factor (TNF). In cells stimulated with PMA plus A23187, SAS suppressed the phosphorylation of extracellular signal-regulated kinase (ERK)1/2 and c-jun
\end{abstract}

Correspondence to: Dr Dong-Yeul Kwon or Dr Ok-Hwa Kang, Department of Oriental Pharmacy, College of Pharmacy and Wonkwang-Oriental Medicines Research Institute, Institute of Biotechnology, Wonkwang University, Iksan-daero, Iksan, Jeonbuk 570-749, Republic of Korea

E-mail: sssimi@wku.ac.kr

E-mail: kangokhwa@hanmail.net

${ }^{*}$ Contributed equally

Key words: salidroside, mast cells, pro-inflammatory cytokines, nuclear factor- $\kappa \mathrm{B}$
N-terminal kinase 1/2 (JNK1/2), but not that of p38 MAPK. SAS suppressed the expression of $N F-\kappa B$ in the nucleus. On the whole, our results suggest that SAS exerts an anti-inflammatory effect by inhibiting the production of pro-inflammatory cytokines through the blocking of the NF- $\mathrm{KB}$ and MAPK signaling pathways.

\section{Introduction}

According to the current understanding of the pathophysiology of allergic diseases, mast cells play a key role in inflammation, and are well known for their influential effector functions in allergic disorders and reactions $(1,2)$. The human mast cell line-1 (HMC-1) originates from a patient with mastocytosis (3) and these cells do not express the high-affinity IgE-receptor FceR1 $(4,5)$. The lack of FceR1 in HMC-1 cells has led to the use of physiological stimuli, such as calcium ionophores and phorbol esters to activate these cells, by many researchers. Previous studies have demonstrated that HMC-1 cells express a wide range of cytokines, which can be synthesized, stored and released after stimulation (6,7). For example, mast cells release pro-inflammatory cytokines and chemokines, such as interleukin (IL)-6, IL-8, granulocyte macrophage colony-stimulating factor (GM-CSF), tumor necrosis factor- $\alpha$ (TNF- $\alpha$ ) and inflammatory mediators, including histamine, leukotrienes and serotonin $(8,9)$. The cytokines released from mast cells transform the terminal microenvironment and attract neutrophils and basophils (10). TNF- $\alpha$ is a pleiotropic pro-inflammatory cytokine that plays an important role in several pathological conditions related to inflammation and infection; the role of TNF in malignancies and inflammatory disorders, such as arthritis has been reviewed extensively (11). The pro-inflammatory activities of IL-6 include the recruitment of inflammatory cells, the inhibition of the apoptosis of inflammatory cells, and the inhibition of regulatory T-cell differentiation (12). IL-8 is the most potent chemokine that has been studied thus far and 
is responsible for inducing chemotaxis, which is the directed migration of cells to a site of inflammation $(13,14)$.

The mitogen-activated protein kinases (MAPKs) include extracellular signal-regulated kinase (ERK), p38 and c-Jun N-terminal kinase (JNK). Each MAPK signaling pathway consists of at least three components, a MAP kinase kinase kinase (MAP3K), MAPK kinase (MAP2K) and MAPK. The MAPK pathways are activated by numerous extracellular and intracellular stimuli, including peptide growth factors, cytokines, hormones and various cellular stressors. Studies on the effects of dominant-interfering or constitutively activated forms of various components of the JNK, p38 and ERK signaling pathways have reported that the activation of JNK and p38 and the coincident inhibition of ERK are significant for the induction of apoptosis. The JNK and p38 signaling pathways are activated by pro-inflammatory cytokines, such as TNF- $\alpha$ in response to cellular stresses $(15,16)$.

Over the past decade, the pharmacological activities have been reported for plants of the Rhodiola genus, such as antihypoxic, antifatigue, antioxidant and anticancer effects, and their effects on anti-apoptotic processes in cells have also been reported $(17,18)$. The Rhodiola rosea $\mathrm{L}$. roots contain a variety of compounds that may contribute to its pharmacological effects, including phenols, polyphenols, rosavin, rosin, rosarin, organic acids, terpenoids, phenolcarbonic acids and their derivatives, flavonoids, anthraquinones and alkaloids (19-23). Salidroside [2-(4-hydroxyphenyl)ethyl $\beta$-D-glucopyranoside (SAS)] is a glucoside of tyrosol found in the plant, Rhodiola rosea $\mathrm{L}$. and it possesses a number of pharmacological properties, including anti-aging, anti-fatigue, antioxidant, anticancer and anti-inflammatory properties (24-26). SAS is a powerful antiinflammatory agent in asthma $(27,28)$. However, the potential effects of SAS against phorbol-12-myristate-13-acetate (PMA) plus A23187-induced inflammation in HMC-1 cells have not yet been fully investigated. Thus, in this study, to elucidate the molecular mechanisms responsible for the pharmacological and biochemical activities of SAS, we examine the effects of SAS on pro-inflammatory mediators in HMC-1 cells stimulated with PMA plus A23187.

\section{Materials and methods}

Reagents and antibodies. Salidroside (chemical structure shown in Fig. 1) was purchased from Sigma-Aldrich (St. Louis, MO, USA) and dissolved in dimethyl sulfoxide (DMSO); the final concentration of DMSO was adjusted to $<0.01 \%(\mathrm{v} / \mathrm{v})$ in the culture medium. PMA and the calcium ionophore, A23187 (calcymycin; $\mathrm{C}_{29} \mathrm{H}_{37} \mathrm{~N}_{3} \mathrm{O}_{6}$ ), were purchased from Sigma-Aldrich. The CellTiter $96^{\circledR}$ AQueous One Solution Cell Proliferation assay (MTS) system was purchased from Promega (Madison, WI, USA). Iscove's modified Dulbecco's medium (IMDM) was obtained from Welgene (Daegu, Korea). Anti-human TNF- $\alpha$ (555212), anti-IL-6 (555220) and anti-IL-8 (555244) antibodies, biotinylated anti-human TNF- $\alpha$ (51-26372E), anti-IL-6 (51-26452E) and IL-8 (51-26542E) antibodies, and recombinant human TNF- $\alpha$ (51-26376E), IL-6 (51-26456E) and anti-IL-8 (51-26546E) antibodies were obtained from BD Pharmingen (San Diego, CA, USA). Antiphosphorylated (p-)ERK1/2 (sc-7383), anti-p-JNK1/2 (sc-6254), anti-p-p38 (sc-7973), anti-ERK1/2 (sc-93), anti-JNK1/2 (sc-571), anti-p38 (sc-535), anti- $\beta$-actin (sc-47778), anti-NF-кB (sc-8008) and anti-rabbit antibodies were obtained from Santa Cruz Biotechnology, Inc. (Santa Cruz, CA, USA). The reverse transcription kit was purchased from Qiagen (Valencia, CA, USA), and nuclear and cytoplasmic extraction reagents were purchased from Thermo Scientific (Waltham, MA, USA).

Cell culture. The human leukemic mast cell line, HMC-1, was obtained from the Korea Research Institute of Bioscience and Biotechnology (Daejeon, Korea) and grown in IMDM supplemented with $10 \%$ heat-inactivated fetal bovine serum (FBS), $2 \mathrm{mM}$ glutamine, $100 \mathrm{IU} / \mathrm{ml}$ penicillin, $50 \mu \mathrm{g} / \mathrm{ml}$ streptomycin and $1.2 \mathrm{mM} \alpha$-thioglycerol at $37^{\circ} \mathrm{C}$ under $5 \% \mathrm{CO}_{2}$ in air.

MTS assay. For the analysis of cell viability by MTS assay, we used the manufacturer's procedure for the AG ProtocolCellTiter $96^{\circledR}$ AQueous One Solution Cell Proliferation assay. Cell aliquots $\left(5 \times 10^{4}\right)$ were seeded in microplate wells and treated with SAS $(10,25,50$ and $100 \mu \mathrm{M})$ for $30 \mathrm{~min}$. The following day, the cells were incubated with $20 \mu \mathrm{l}$ of MTS solution for $2 \mathrm{~h}$ at $37^{\circ} \mathrm{C}$ under $5 \% \mathrm{CO}_{2}$ and $95 \%$ air. An automatic microplate reader (Molecular Devices, Sunnyvale, CA, USA) was used to read the absorbance of each well at $490 \mathrm{~nm}$.

Enzyme-linked immunosorbent assay (ELISA). The HMC-1 cells were treated with various concentrations of SAS (10, 25 and $50 \mu \mathrm{M})$ for $1 \mathrm{~h}$ prior to stimulation with PMA $(50 \mathrm{nM})$ plus A23187 $(1 \mu \mathrm{M})$. An ELISA was used to assay the protein levels of IL-6, IL- 8 and TNF-8 in the culture supernatants. To measure the cytokine levels, we used a modified ELISA. First, we conducted a sandwich ELISA for IL-6, IL-8 and TNF-8 in triplicate in 96-well ELISA plates (Nunc, Roskilde, Denmark). The supernatant was then transferred to a new microcentrifuge tube, and the cytokines were quantified using ELISA. ELISA plates (Falcon; Becton-Dickinson Labware, Franklin Lakes, NJ, USA) were coated overnight at $4^{\circ} \mathrm{C}$ with anti-human IL-6, anti-IL- 8 and anti-TNF- $\alpha$ monoclonal antibodies in coating buffer (0.1 M carbonate, $\mathrm{pH} 9.5)$ and then washed 3 imes with phosphate-buffered saline (PBS) containing 0.05\% Tween-20. The non-specific protein binding sites were blocked with assay diluent (PBS containing 10\% FBS, pH 7.0) for at least $1 \mathrm{~h}$. After washing the plates again, the test sample or recombinant IL-6, IL- 8 and TNF- $\alpha$ standards were added. Following incubation for $2 \mathrm{~h}$, a working detector (biotinylated anti-human IL-6, anti-IL- 8 and anti-TNF- $\alpha$ monoclonal antibodies and streptavidin-horseradish peroxidase reagent) were added followed by incubation for $1 \mathrm{~h}$. The non-specific protein binding sites were blocked. Subsequently, substrate solution [tetramethylbenzidine (TMB)] was added to the wells followed by incubation for $30 \mathrm{~min}$ in the dark before the reaction was terminated by the addition of $1 \mathrm{M} \mathrm{H}_{3} \mathrm{PO}_{4}$. The absorbance was read at $450 \mathrm{~nm}$. All subsequent steps were carried out at room temperature, and all standards and samples were assayed in triplicate.

Reverse transcription-polymerase chain reaction (RT-PCR). Using an Easy Blue total RNA extraction kit (Intron Biotechnology, Gyeonggi-do, Korea) we isolated total RNA from the HMC-1 cells in accordance with the specifications of the manufacturer. The total RNA was dissolved in DEPC-treated distilled water. A spectrophotometer (NanoDrop Technologies, 


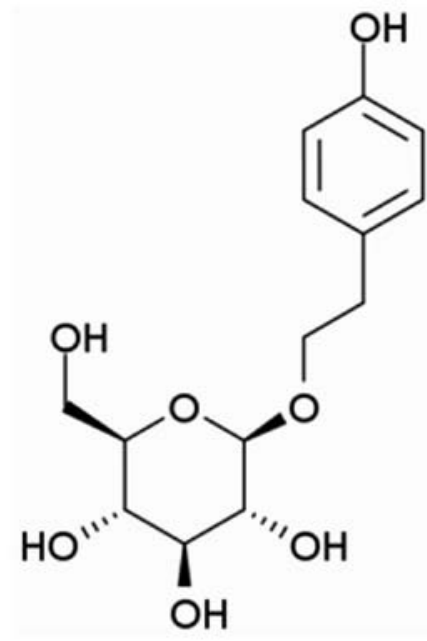

Figure 1. Chemical structure of salidroside (SAS).

Wilmington, DE, USA) was used to assess RNA purity by measuring the ratio of the absorbance at 260 and $280 \mathrm{~nm}$; only RNA samples with a value in the 1.6-2.0 range were used. A cDNA synthesis kit (Qiagen, Valencia, CA, USA) was used for $2 \mathrm{~min}$ at $42^{\circ} \mathrm{C}, 30 \mathrm{~min}$ at $42^{\circ} \mathrm{C}$, and $30 \mathrm{~min}$ at $95^{\circ} \mathrm{C}$ to reverse transcribe each sample into cDNA. The primer sequences were as follows: IL-6 forward, 5'-GATGGATGCTTCCA ATCTGGAT-3' and reverse, 5'-AGTTCTCCATAGAGAA CAACATA-3'; IL-8 forward, 5'-TGTGCTCTCCAAAT TTTTTTTACTG-3' and reverse, 5'-CTCTCTTTCCTCTTT AATGTCCAGC-3; TNF- $\alpha$ forward, 5'-CACCAGCTGGTTA TCTCTCAGCTC-3' and reverse, 5'-CGGGACGTGGA GCTGGCCGAGGAG-3'; glyceraldehyde 3-phosphate dehydrogenase (GAPDH) forward, 5'CCATGTTCGTCAT GGGTGTGAACCA-3' and reverse, 5'-GCCAGTAGAGG CAGGGATGATGTTC-3'. Finally, following electrophoresis on a $2 \%$ agarose gel, the expression levels were confirmed using a UV detector (ImageQuant LAS 500; GE Healthcare Life Science, Chicago, IL, USA).

Preparation of cytoplasmic and nuclear extracts. Nuclear extraction reagent (NER) and cytoplasmic extraction reagent (CER) were used to extract the nucleus and cytoplasm. A cell volume of $20 \mu \mathrm{l}$ corresponded to a volume ratio of CER I:CER II:NER (200:11:100 $\mu$ l, respectively). A tube containing CER I was first vortexed vigorously on the highest setting for $1 \mathrm{sec}$ to fully suspend the cell pellet. The tube was then incubated on ice for $10 \mathrm{~min}$. Ice-cold CER II was then added to the tube, and the tube was vortexed for $5 \mathrm{sec}$ on the highest setting. The tube was then incubated on ice for $1 \mathrm{~min}$ before being vortexed for $5 \mathrm{sec}$ on the highest setting. The tube was then centrifuged at 13,000 rpm for 5 min on a microcentrifuge (Centrifuge 5415F; Eppendorf, Hamburg, Germany). The supernatant (cytoplasmic extract) was then immediately transferred to a clean, pre-chilled tube and stored until needed. Ice-cold NER was added to the pellet, and the tube was vortexed on the highest setting for $15 \mathrm{sec}$. The sample was placed on ice and vortexed for $15 \mathrm{sec}$ every $10 \mathrm{~min}$, for a total of $40 \mathrm{~min}$. The tube was then centrifuged at 13,000 rpm for $5 \mathrm{~min}$ on a microcentrifuge. The supernatant (nuclear extract) was then immediately transferred to a clean, pre-chilled tube.

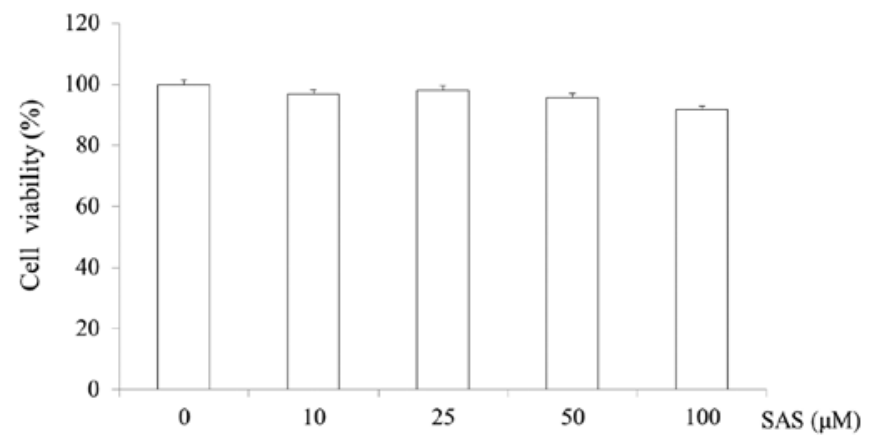

Figure 2. Effect of salidroside (SAS) on the viability of the human mast cell line-1 (HMC-1). Cell viability was evaluated by MTS assay. HMC-1 cells were treated with the indicated concentrations of SAS for $24 \mathrm{~h}$. Data are the means concentration of SAS for 2 measurements from 3 separate experiments.

Western blot analysis. The HMC-1 cells $\left(5 \times 10^{6}\right.$ cells/well) were stimulated with PMA $(50 \mathrm{nM})$ plus A23187 $(1 \mu \mathrm{M})$. The cell lysates were prepared in a sample buffer containing sodium dodecyl sulfate (SDS). The samples were heated at $95^{\circ} \mathrm{C}$ for $5 \mathrm{~min}$ and briefly cooled on ice. Following centrifugation at 13,000 rpm for $5 \mathrm{~min}$, the proteins in the cell lysates were separated by $12 \%$ SDS-polyacrylamide gel electrophoresis (SDS-PAGE) and transferred onto a nitrocellulose membrane. The membrane was then blocked with 5\% skim milk in PBS-Tween-20 for $1 \mathrm{~h}$ at room temperature and then incubated with anti-MAPKs, anti- $\beta$-actin and anti-NF- $\kappa \mathrm{B}$ antibodies overnight. After washing the blot in Tris-buffered saline and Tween-20 (TBST) 3 times, it was incubated with a secondary antibody for $1 \mathrm{~h}$, and then the antibody-specific proteins were visualized using an ECL ${ }^{\mathrm{TM}}$ prime western blotting detection reagent in accordance with the recommended procedure (Amersham Corp., Newark, NJ, USA).

Statistical analysis. Statistical analysis was performed using one-way analysis of variance (ANOVA) followed by Dunnett's t-test for multiple comparisons and the Student's t-test for single comparisons. The data from the experiments are presented as the means \pm SEM. The numbers of independent experiments assessed are provided in the figure legends.

\section{Results}

Cytotoxicity of SAS in HMC-1 cells. The cytotoxicity of SAS was evaluated by MTS assay. SAS was found to not affect the viability of the HMC-1 cells at concentrations of 10, 25, 50 and $100 \mu \mathrm{M}$. The cell viability of the cells treated with $100 \mu \mathrm{M}$ SAS was $91.6 \%$ (Fig. 2).

Effect of SAS on the production of IL-6,IL-8 and TNF- $\alpha$. To evaluate the effects of SAS on the production of IL-6, IL-8 and TNF- $\alpha$, we treated the cells with SAS $(10,25$ and $50 \mu \mathrm{M})$ prior to stimulation with PMA $(50 \mathrm{nM})$ plus A23187 $(1 \mu \mathrm{M})$ for $8 \mathrm{~h}$ and analyzed the levels using ELISA. The levels of IL-6, IL-8, and TNF- $\alpha$ in the HMC-1 cells significantly increased following stimulation with PMA plus A23187 (Figs. 3-5). Pre-treatment of the cells with SAS (10, 25 and $50 \mu \mathrm{M})$ significantly inhibited the increase in the levels of these cytokines in a concentration-dependent manner. The maximal inhibition of 


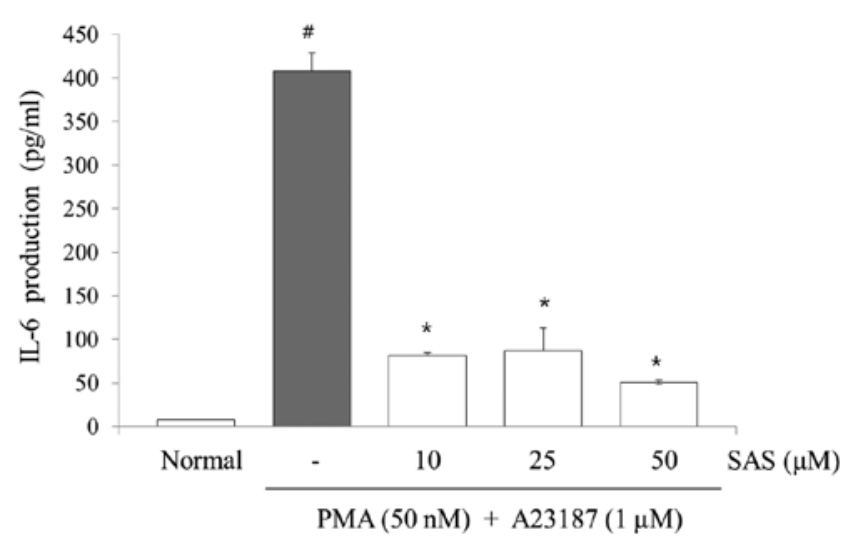

Figure 3. Effect of salidroside (SAS) on interleukin-6 (IL-6) production. HMC-1 cells were treated with SAS $(10,25$ and $50 \mu \mathrm{M})$ before being stimulated with phorbol-12-myristate-13-acetate (PMA, $50 \mathrm{nM}$ ) plus A23187 $(1 \mu \mathrm{M})$ for $8 \mathrm{~h}$. Values are expressed as the means $\pm \mathrm{SE}$ ( $\mathrm{n}=3$ experiments). ${ }^{\text {"}} \mathrm{P}<0.05$. vs. normal (untreated cells); ${ }^{*} \mathrm{P}<0.05$. vs. PMA ( $\left.50 \mathrm{nM}\right)$ plus A23187 $(1 \mu \mathrm{M})$-stimulated cells.

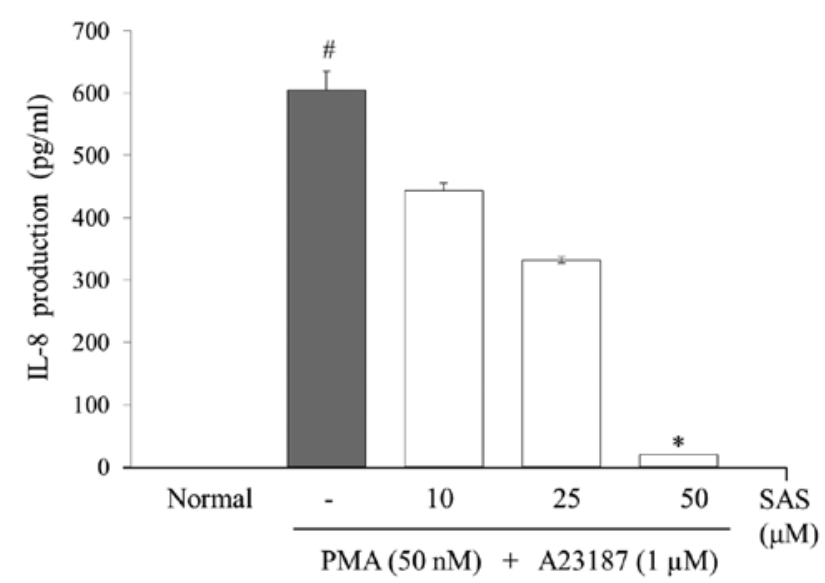

Figure 4. Effect of salidroside (SAS) on interleukin-8 (IL-8) production. HMC-1 cells were treated with SAS $(10,25$ and $50 \mu \mathrm{M}) 1 \mathrm{~h}$ prior to being stimulated with phorbol-12-myristate-13-acetate (PMA) $(50 \mathrm{nM})$ plus A23187 $(1 \mu \mathrm{M})$ for $8 \mathrm{~h}$. Values are expressed as the means $\pm \mathrm{SE}(\mathrm{n}=3$ experiments). ${ }^{*} \mathrm{P}<0.05$. vs. normal (untreated cells); ${ }^{*} \mathrm{P}<0.05$. vs. PMA ( $50 \mathrm{nM}$ ) plus A23187 (1 $\mu \mathrm{M})$-stimulated cells.

IL-6, IL- 8 and TNF- $\alpha$ production by SAS $(50 \mu \mathrm{M})$ was 88,94 and 63\%, respectively (Figs. 3-5).

Effect of SAS on IL-6,IL-8 and TNF- $\alpha$ gene expression. The IL-6, IL- 8 and TNF- $\alpha$ gene expression levels were analyzed by RT-PCR. The increase in the expression of IL-6, IL-8 and TNF- $\alpha$ induced by PMA plus A23187 was inhibited by pretreatment of the cells with SAS. In particular, SAS $(50 \mu \mathrm{M})$ significantly inhibited the PMA plus A23187-induced increase in the expression of IL-6 and IL-8 (Fig. 6).

Effect of SAS on the activation of MAPKs. In order to elucidate the mechanisms underlying the effect of SAS, we examined the effect of SAS on MAPK activation. The stimulation of the HMC-1 cells with PMA plus A23187 resulted in an increased phosphorylation of all three types of MAPKs (ERK, JNK and p38) after $1 \mathrm{~h}$. SAS reduced the PMA plus A23187-induced expression of p-ERK1/2 and p-JNK1/2 (Fig. 7). However, SAS had no effect on the levels of p-p38 (Fig. 7).

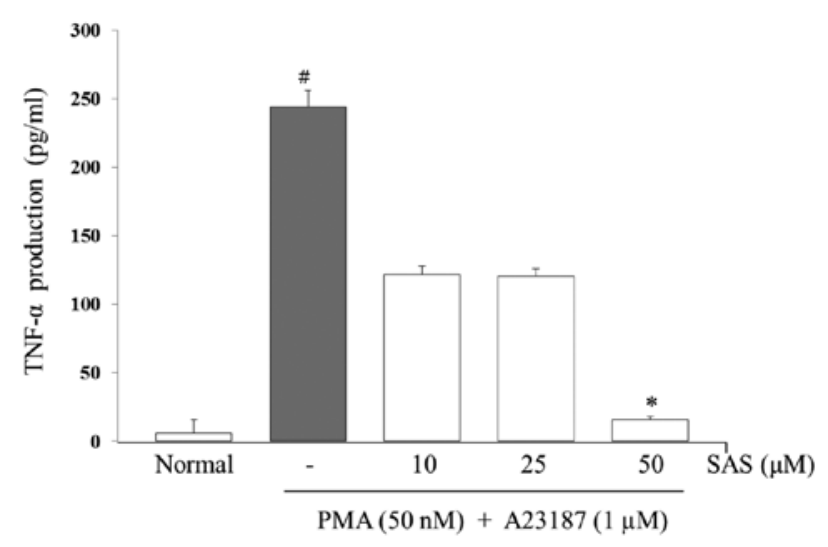

Figure 5. Effect of salidroside (SAS) on tumor necrosis factor (TNF)- $\alpha$. HMC-1 cells were treated with SAS $(10,25$ and $50 \mu \mathrm{M})$ for $1 \mathrm{~h}$ prior to being stimulated with phorbol-12-myristate-13-acetate (PMA) $(50 \mathrm{nM})$ plus A23187 $(1 \mu \mathrm{M})$ for $8 \mathrm{~h}$. Values are expressed as the means $\pm \mathrm{SE}(\mathrm{n}=3$ experiments). " $\mathrm{P}<0.05$. vs. normal (untreated cells); ${ }^{*} \mathrm{P}<0.05$. vs. PMA $(50 \mathrm{nM})$ plus A23187 $(1 \mu \mathrm{M})$-stimulated cells.

A
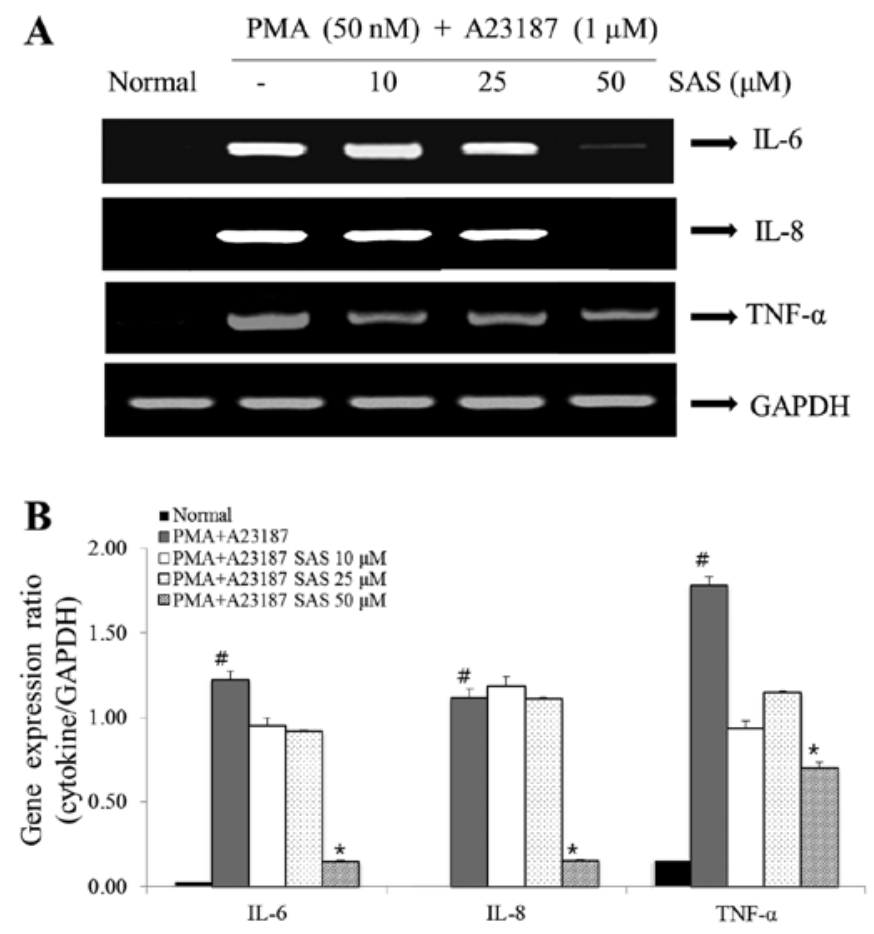

Figure 6. (A and B) Effect of salidroside (SAS) on the mRNA expression of interleukin (IL)-6, IL-8 and tumor necrosis factor (TNF)- $\alpha$ as analyzed by RT-PCR. HMC-1 cells were treated with SAS $(10,25$ and $50 \mu \mathrm{M})$ for $1 \mathrm{~h}$ prior to being stimulated with phorbol-12-myristate-13-acetate (PMA) $(50 \mathrm{nM})$ plus A23187 $(1 \mu \mathrm{M})$ for $8 \mathrm{~h}$. Values are expressed as the means $\pm \mathrm{SE}(\mathrm{n}=3$ experiments). " $\mathrm{P}<0.05$. vs. normal (untreated cells); $\mathrm{P}<0.05$. vs. PMA (50 nM) plus A23187 $(1 \mu \mathrm{M})$-stimulated cells.

Effect of SAS on the expression of $N F-\kappa B$. To evaluate the mechanisms through which SAS affected the gene expression of pro-inflammatory cytokines, we examined the effects of SAS on NF- $\kappa \mathrm{B}$ expression. The expression of pro-inflammatory cytokines is regulated by the transcription factor, $\mathrm{NF}-\kappa \mathrm{B}$ (8). Stimulation of the HMC-1 cells with PMA plus A23187 induced the nuclear translocation of $\mathrm{NF}-\kappa \mathrm{B}$ p65 after $2 \mathrm{~h}$ of incubation (8). SAS inhibited the PMA plus A23187-

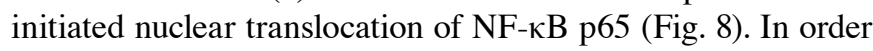


A
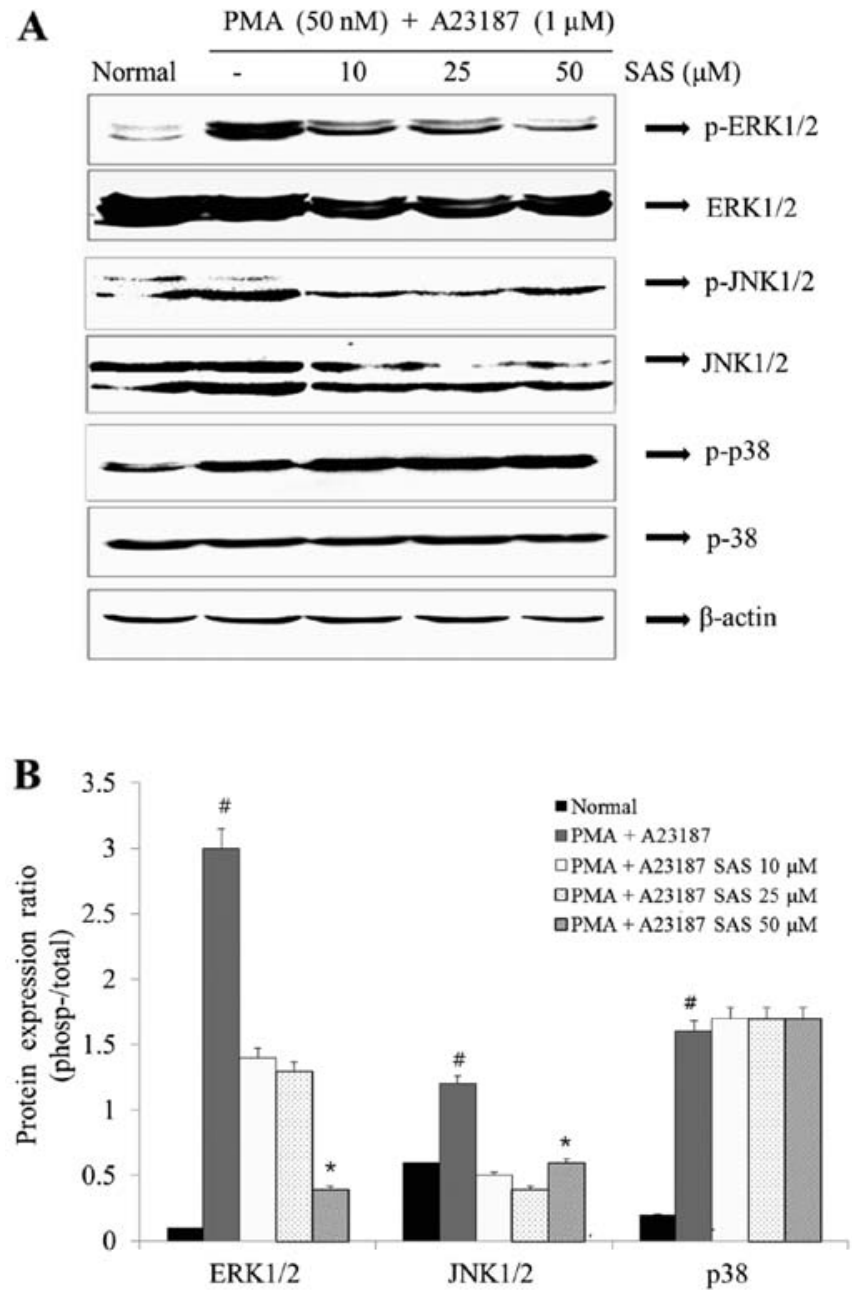

Figure 7. (A and B) Effect of salidroside (SAS) on the activation of mitogenactivated protein kinases (MAPKs) as analyzed by western blot analysis. HMC-1 cells were treated with SAS $(10,25$ and $50 \mu \mathrm{M})$ for $1 \mathrm{~h}$ prior to being stimulated with phorbol-12-myristate-13-acetate (PMA) $(50 \mathrm{nM})$ plus A23187 $(1 \mu \mathrm{M})$ for $8 \mathrm{~h}$. Values are expressed as the means $\pm \mathrm{SE}(\mathrm{n}=3$ experiments). " $\mathrm{P}<0.05$. vs. normal (untreated cells); ${ }^{*} \mathrm{P}<0.05$. vs. PMA ( $\left.50 \mathrm{nM}\right)$ plus A23187 (1 $\mu \mathrm{M})$-stimulated cells.

to confirm the inhibitory effect of SAS on NF-kB expression, we examined the effect of SAS on NF- $\kappa B$-dependent protein expression (Fig. 8).

\section{Discussion}

Previous studies on plant-derived anti-inflammatory compounds have investigated the potential inhibitory effects of natural products using in vivo and in vitro methods. These studies suggest an important role for SAS as a potential chemoprevention agent due to its anti-inflammatory effects, and anticancer effects (24-26). The aim of the present study was to examine the effects of SAS on the production of TNF- $\alpha$, IL-6 and IL-8 in PMA plus A23187-stimulated HMC-1 cells, since these cytokines have potent inflammatory effects.

Mast cells contain potent mediators, including histamine, heparin, proteinases, leukotrienes and pro-inflammatory cytokines; all of which potentially contribute to inflammatory processes (29). Pro-inflammatory cytokines, particularly TNF- $\alpha$, IL- 6 and IL-8, play critical biological roles in allergic
A
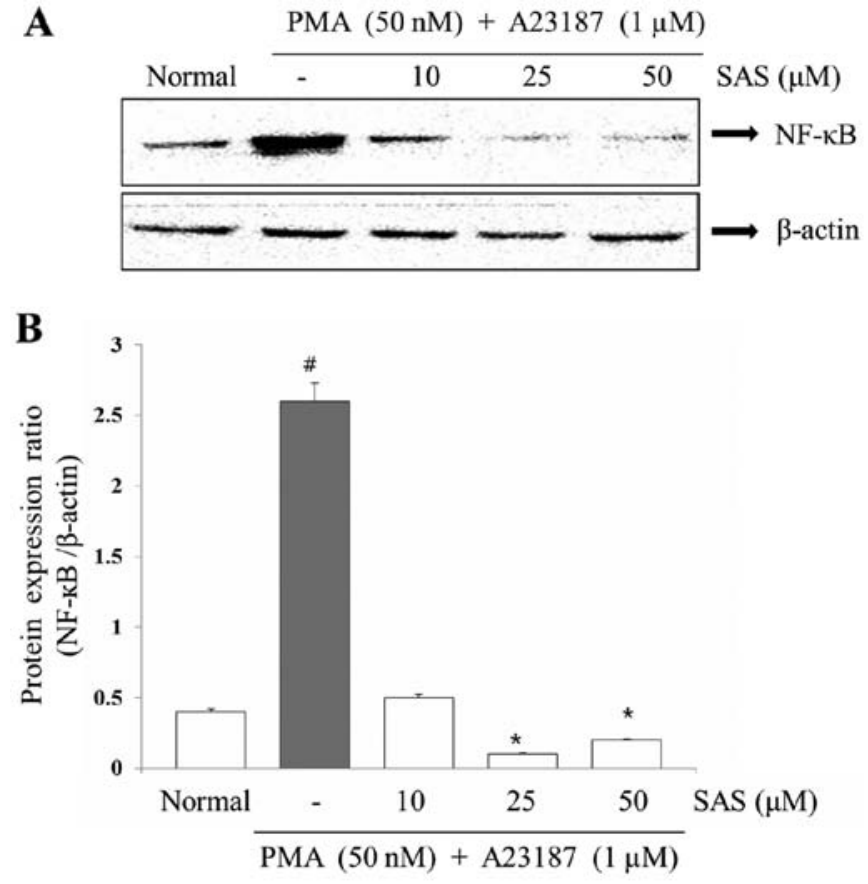

Figure 8. (A and B) Effect of salidroside (SAS) on the expression of nuclear factor $\kappa$-light-chain-enhancer of activated B cells (NF- $\kappa$ B) was analyzed by western blot analysis. HMC-1 cells were treated with SAS (10, 25 and $50 \mu \mathrm{M})$ for $1 \mathrm{~h}$ prior to being stimulated with phorbol-12-myristate-13-acetate (PMA) $(50 \mathrm{nM})$ plus A23187 $(1 \mu \mathrm{M})$ for $2 \mathrm{~h}$. Values are expressed as the means $\pm \mathrm{SE}\left(\mathrm{n}=3\right.$ experiments). ${ }^{\#} \mathrm{P}<0.05$. vs. normal (untreated cells); ${ }^{*} \mathrm{P}<0.05$. vs. PMA (50 nM) plus A23187 (1 $\mu \mathrm{M})$-stimulated cells.

inflammation. These cytokines are released as stored cytokines and can be newly synthesized during mast cell activation (30). TNF- $\alpha$ promotes inflammation, granuloma formation and tissue fibrosis and is thought to be an initiator of cytokinerelated inflammatory responses by promoting cytokine production (31). Previous studies have indicated that reduced amounts of TNF- $\alpha$ and IL- 6 released from mast cells is key to reducing the symptoms of allergic inflammation $(32,33)$. IL-8 released from mast cells acts on surrounding cells, such as neutrophils and eosinophils, and induces the migration and activation of inflammatory effector cells (34). In this study, we found that SAS reduced the production of TNF- $\alpha$, IL- 6 and IL-8 in PMA plus A23187-stimulated HMC-1 cells. Increases in levels of intracellular calcium induce the release of biological mediators, including TNF- $\alpha$, IL-8 and IL- 6 . It has also been reported that the release of intracellular calcium from internal stores is required for MAPK activation $(35,36)$. MAPKs have been reported to be involved in important pathways associated with the differentiation, activation, proliferation, degranulation and migration of various immune cells, airway smooth muscle and epithelial cells (37). We also investigated whether pre-treatment SAS would interfere with the MAPK signaling pathways. The results from western blot analysis indicated that the expression of p-ERK, p-JNK, and p-p38 considerably increased in the PMA plus A23187-stimulated mast cells, as compared to the untreated mast cells. However, the expression of p-ERK and p-JNK proteins significantly decreased following treatment with SAS, but no decreases were observed in p-p38 expression; therefore, it is thought that SAS is not 
involved in the p38 pathway. The expression of inflammatory cytokines requires the phosphorylation of MAPKs. In this study, no significant changes were found in the expression of total ERK, JNK and p38 between the different groups. The ERK pathway is predominantly activated by mitogenic and proliferative stimuli, whereas the JNK and p38 MAPK pathways respond to environmental stresses (38). While the exact nature of the involvement of the ERK1/2 pathway remains elusive, nuclear retention, dimerization, phosphorylation and release from cytoplasmic anchors have been shown to play a role (39). The JNKs are greatly activated in response to cytokines, growth factor deprivation, DNA-damaging agents, some $\mathrm{G}$ protein-coupled receptors, serum and growth factors. In mammalian cells, the p38 pathway is strongly activated by environmental stresses and inflammatory cytokines, but not appreciably by mitogenic stimuli. Additionally, p38 participates in macrophage and neutrophil functional responses, including respiratory burst activity, chemotaxis, granular exocytosis, apoptosis and also mediates T-cell differentiation and apoptosis by regulating $\gamma$-interferon production and regulates the immune response by stabilizing specific cellular mRNAs (40).

$\mathrm{NF}-\kappa \mathrm{B}$ is a transcription factor that induces the transcription of a variety of genes. Many of these genes encode molecules important in inflammatory processes, such as cytokines and adhesion molecules. The role of $\mathrm{NF}-\kappa \mathrm{B}$, in particular its regulation of cytokine production, in allergic inflammation has previously been characterized (41). NF- $\kappa \mathrm{B}$ regulates the expression of multiple inflammatory and immune genes and plays a critical role in chronic inflammatory diseases (42). To evaluate the mechanisms of the inhibition of SAS on the expression of pro-inflammatory cytokines, we examined the effect of SAS on the NF- $\kappa$ B pathway. In this study, SAS decreased the nuclear translocation of NF- $\kappa \mathrm{B}$ p65. These results indicate that the inhibitory effects of SAS on inflammatory cytokines were due to the regulation of the NF- $\kappa \mathrm{B}$ pathway.

In conclusion, our study demonstrates pre-treatment with salidroside significantly inhibits the increase in the levels of TNF- $\alpha$, IL- 6 and IL- 8 induced by PMA plus A23187 in mast cells, suppresses NF- $\kappa$ B p65, ERK1/2 and JNK1/2 expression, and inhibits the upregulation of pro-inflammatory cytokines. Therefore, salidroside may prove to be an effective therapeutic agent for the treatment of inflammation resulting from mast cell-mediated inflammatory responses.

\section{Acknowledgements}

This research was supported by Wonkwang University in 2015.

\section{References}

1. Bischoff SC: Role of mast cells in allergic and non-allergic immune responses: Comparison of human and murine data. Nat Rev Immunol 7: 93-104, 2007.

2. Metz M and Maurer M: Mast cells--key effector cells in immune responses. Trends Immunol 28: 234-241, 2007.

3. Butterfield JH, Weiler D, Dewald G and Gleich GJ: Establishment of an immature mast cell line from a patient with mast cell leukemia. Leuk Res 12: 345-355, 1988.

4. Nilsson G, Blom T, Kusche-Gullberg M, Kjellén L, Butterfield JH, Sundström C, Nilsson K and Hellman L: Phenotypic characterization of the human mast-cell line HMC-1. Scand J Immunol 39: 489-498, 1994.
5. Xia HZ, Kepley CL, Sakai K, Chelliah J, Irani AM and Schwartz LB: Quantitation of tryptase, chymase, FceRI $\alpha$, and FceRI $\gamma$ mRNAs in human mast cells and basophils by competitive reverse transcription-polymerase chain reaction. J Immunol 154: 5472-5480, 1995.

6. Xia YC, Sun S, Kuek LE, Lopata AL, Hulett MD and Mackay GA: Human mast cell line-1 (HMC-1) cells transfected with FceRI $\alpha$ are sensitive to IgE/antigen-mediated stimulation demonstrating selectivity towards cytokine production. Int Immunopharmacol 11: 1002-1011, 2011.

7. Grützkau A, Krüger-Krasagakes S, Kögel H, Möller A, Lippert U and Henz BM: Detection of intracellular interleukin-8 in human mast cells: Flow cytometry as a guide for immunoelectron microscopy. J Histochem Cytochem 45: 935-945, 1997.

8. Kang OH, Jang HJ, Chae HS, Oh YC, Choi JG, Lee YS, Kim JH, Kim YC, Sohn DH and Park H: Anti-inflammatory mechanisms of resveratrol in activated HMC-1 cells: Pivotal roles of NF-kappaB and MAPK. Pharmacol Res 59: 330-337, 2009.

9. Zhu Z, Homer RJ, Wang Z, Chen Q, Geba GP, Wang J, Zhang Y and Elias JA: Pulmonary expression of interleukin-13 causes inflammation, mucus hypersecretion, subepithelial fibrosis, physiologic abnormalities, and eotaxin production. J Clin Invest 103: 779-788, 1999.

10. Kim HH, Bae Y and Kim SH: Galangin attenuates mast cellmediated allergic inflammation. Food Chem Toxicol 57: 209-216, 2013.

11. Kumar A, Abbas W and Herbein G: TNF and TNF receptor superfamily members in HIV infection: New cellular targets for therapy? Mediators Inflamm 2013: 484378, 2013.

12. Rose-John S: IL-6 trans-signaling via the soluble IL-6 receptor: importance for the pro-inflammatory activities of IL-6. Int J Biol Sci 8: 1237-1247, 2012.

13. Zhang N, Xu Y, Zhang B, Zhang T, Yang H, Zhang B, Feng Z and Zhong D: Analysis of interleukin- 8 gene variants reveals their relative importance as genetic susceptibility factors for chronic periodontitis in the Han population. PLoS One 9: e104436, 2014.

14. Remick DG: Interleukin-8. Crit Care Med 33 (Suppl 12): S466-S467, 2005.

15. Kim EK and Choi EJ: Pathological roles of MAPK signaling pathways in human diseases. Biochim Biophys Acta 1802: 396-405, 2010

16. Xia Z, Dickens M, Raingeaud J, Davis RJ and Greenberg ME: Opposing effects of ERK and JNK-p38 MAP kinases on apoptosis. Science 270: 1326-1331, 1995.

17. Mao Y, Li Y and Yao N: Simultaneous determination of salidroside and tyrosol in extracts of Rhodiola L. by microwave assisted extraction and high-performance liquid chromatography. J Pharm Biomed Anal 45: 510-515, 2007.

18. Zheng W and Wang SY: Antioxidant activity and phenolic compounds in selected herbs. J Agric Food Chem 49: 5165-5170, 2001.

19. Peschel W, Prieto JM, Karkour C and Williamson EM: Effect of provenance, plant part and processing on extract profiles from cultivated European Rhodiola rosea L. for medicinal use. Phytochemistry 86: 92-102, 2013.

20. Perfumi M and Mattioli L: Adaptogenic and central nervous system effects of single doses of 3\% rosavin and $1 \%$ salidroside Rhodiola rosea L. extract in mice. Phytother Res 21: 37-43, 2007.

21. Yousef GG, Grace MH, Cheng DM, Belolipov IV, Raskin I and Lila MA: Comparative phytochemical characterization of three Rhodiola species. Phytochemistry 67: 2380-2391, 2006.

22. Ming DS, Hillhouse BJ, Guns ES, Eberding A, Xie S, Vimalanathan $\mathrm{S}$ and Towers GH: Bioactive compounds from Rhodiola rosea (Crassulaceae). Phytother Res 19: 740-743, 2005.

23. Richard P, Brown MD, Patricia L, Gerbarg MD, Zakir Ramazanov DS: Rhodiola rosea: A phytomedicinal overview. HerbalGram 56: 40-52, 2002.

24. Zhu Y, Shi YP, Wu D, Ji YJ, Wang X, Chen HL, Wu SS, Huang DJ and Jiang W: Salidroside protects against hydrogen peroxideinduced injury in cardiac $\mathrm{H} 9 \mathrm{c} 2$ cells via PI3K-Akt dependent pathway. DNA Cell Biol 30: 809-819, 2011.

25. Tan CB, Gao M, Xu WR, Yang XY, Zhu XM and Du GH: Protective effects of salidroside on endothelial cell apoptosis induced by cobalt chloride. Biol Pharm Bull 32: 1359-1363, 2009.

26. Chen X, Zhang Q, Cheng Q and Ding F: Protective effect of salidroside against $\mathrm{H}_{2} \mathrm{O}_{2}$-induced cell apoptosis in primary culture of rat hippocampal neurons. Mol Cell Biochem 332: 85-93, 2009. 
27. Wang J, Xiao L, Zhu L, Hu M, Wang Q and Yan T: The effect of synthetic salidroside on cytokines and airway inflammation of asthma induced by diisocyanate (TDI) in mice by regulating GATA3/T-bet. Biochem Biophys Res Commun 451: 79-85, 2014.

28. Yan GH and Choi YH: Salidroside attenuates allergic airway inflammation through negative regulation of nuclear factorkappa B and p38 mitogen-activated protein kinase. J Pharmacol Sci 126: 126-135, 2014

29. Bradding P and Holgate ST: Immunopathology and human mast cell cytokines. Crit Rev Oncol Hematol 31: 119-133, 1999.

30. Hide I, Toriu N, Nuibe T, Inoue A, Hide M, Yamamoto S and Nakata Y: Suppression of TNF-alpha secretion by azelastine in a rat mast (RBL-2H3) cell line: Evidence for differential regulation of TNF-alpha release, transcription, and degranulation. J Immunol 159: 2932-2940, 1997.

31. Vandenabeele P, Declercq W, Van Herreweghe F and Vanden Berghe T: The role of the kinases RIP1 and RIP3 in TNF-induced necrosis. Sci Signal 3: re4, 2010.

32. Walczak H: TNF and ubiquitin at the crossroads of gene activation, cell death, inflammation, and cancer. Immunol Rev 244 9-28, 2011.

33. Mican JA, Arora N, Burd PR and Metcalfe DD: Passive cutaneous anaphylaxis in mouse skin is associated with local accumulation of interleukin-6 mRNA and immunoreactive interleukin-6 protein. J Allergy Clin Immunol 90: 815-824, 1992.

34. Lin TJ, Garduno R, Boudreau RT and Issekutz AC: Pseudomonas aeruginosa activates human mast cells to induce neutrophil transendothelial migration via mast cell-derived IL-1 alpha and beta. J Immunol 169: 4522-4530, 2002.
35. Law M, Morales JL, Mottram LF, Iyer A, Peterson BR and August A: Structural requirements for the inhibition of calcium mobilization and mast cell activation by the pyrazole derivative BTP2. Int J Biochem Cell Biol 43: 1228-1239, 2011.

36. Crossthwaite AJ, Hasan S and Williams RJ: Hydrogen peroxidemediated phosphorylation of ERK1/2, Akt/PKB and JNK in cortical neurones: Dependence on $\mathrm{Ca}(2+)$ and PI3-kinase. J Neurochem 80: 24-35, 2002.

37. Duan W and Wong WS: Targeting mitogen-activated protein kinases for asthma. Curr Drug Targets 7: 691-698, 2006.

38. Mizuno T, Hisamoto N, Terada T, Kondo T, Adachi M, Nishida E, Kim DH, Ausubel FM and Matsumoto K: The Caenorhabditis elegans MAPK phosphatase VHP-1 mediates a novel JNK-like signaling pathway in stress response.EMBO J 23: 2226-2234, 2004.

39. Cargnello $M$ and Roux PP: Activation and function of the MAPKs and their substrates, the MAPK-activated protein kinases. Microbiol Mol Biol Rev 75: 50-83, 2011.

40. Roux PP and Blenis J: ERK and p38 MAPK-activated protein kinases: A family of protein kinases with diverse biological functions. Microbiol Mol Biol Rev 68: 320-344, 2004.

41. DiDonato JA, Mercurio F and Karin M: NF- $\mathrm{kB}$ and the link between inflammation and cancer. Immunol Rev 246: 379-400, 2012.

42. Pasparakis M: Role of NF- $\mathrm{KB}$ in epithelial biology. Immunol Rev 246: 346-358, 2012. 